\title{
NEW SYNTHESIS METHOD TO OBTAIN A METHACRYLIC MONOMER WITH A PYRYLIUM GROUP
}

\author{
SAÚL E. BUSTAMANTE ${ }^{a}$ AND BERNABÉ L. RIVAS*,a
}

${ }^{a}$ Department of Polymer, Faculty of Chemistry, University of Concepción, Casilla 160-C, Concepción, Chile. e-mail: brivas@udec.cl

\begin{abstract}
Methacrylic monomers with pyrylium salt derivatives are widely used to detect nucleophilic species. A new synthesis method has been used to obtain a pyrylium salt that is trisubstituted with phenyl groups at positions 2,4, and 6 . The phenyl group of the 4-position has a metacrylate group in the para-position. The new synthesis method implies the esterification of 4-hydroxybenzaldehyde, using methacrylic anhydride. The formed compound react with acetophenone to form the pyrylium derivative. The yields of both reactions are greater than those previously reported in the literature.
\end{abstract}

\section{INTRODUCTION}

Aromatic heterocycles are substances that are known for their multiple properties and applications. They are present in various biological processes such as chlorophyll-catalyzed photosynthesis, oxygen, and carbon dioxide transport in blood by hemoglobin and storage and delivery of chemical energy through ATP. Moreover, some aromatic heterocycles have conductive properties and others are dyes. ${ }^{1}$ Within these colored substances there is a well-known family called pyrylium salts, whose compound structures have a pyrylium cation (see Fig.1). Because of their fluorescence properties, some pyrylium salts are used as internal labeling reagents in photographic films, where they emit specific colors when exposed to ultraviolet light. ${ }^{2}$ Among other uses of these salts, their roles as phototherapeutic agents, ${ }^{3}$ anticarcinogenic agents ${ }^{4}$ or chemosensors to detect toxic anions such as cyanide ${ }^{5}$ are highlighted.

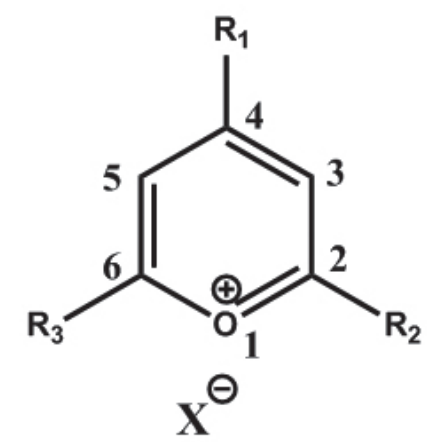

Figure 1. Pyrylium salt. $\mathrm{X}^{-}$is a non-nucleophilic anion.

The pyrylium cation is formed by replacing one $\mathrm{CH}$ group of a benzene with a positively charged oxygen atom $\left(\mathrm{O}^{+}\right)$. Because pyrylium is a cation, the aromaticity of the ring is highly disturbed because of the high electronegativity of the oxygen atom, ${ }^{6}$ as evidenced in the Index of Bird's aromaticity for sixmembered heterocycles (benzene $=100$; pyrylium cation $=68.5)^{1}$. Like all sixmember rings with one heteroatom that is more electronegative than carbon, the electronic distribution of pyrylium cations can be represented by its resonance structures (see Fig. 2 (A-D)). The atoms at positions 2 and 6 have the highest partial positive charge, followed by those at position 4 .

A nucleophilic attack commonly opens the ring and produces other heterocycles, which are useful as starting materials in synthesis processes Pyrylium cations are heterocycles that are notably deficient in $\pi$-electrons, but are stable when they are linked to non-nucleophilic anions (counterions). ${ }^{8}$

The most common salts contain mono- and multi-atomic anions, such as fluoride, chloride, bromide, tetrafluoroborate, perchlorate, ${ }^{9} 2$-naphthalenesul fonate, ${ }^{10}$ trifluoromethanesulfonate, ${ }^{11}$ hexafluorophosphate, ${ }^{12}$ tosylate,${ }^{13}$ among others.

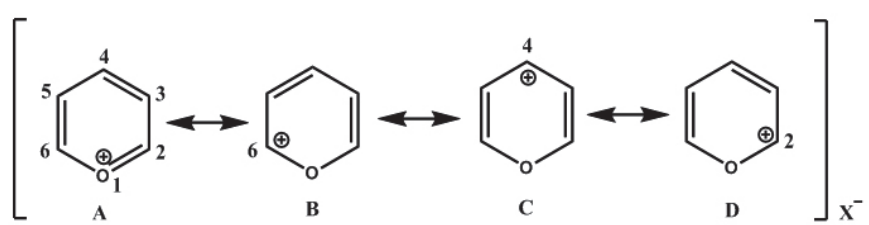

Figure 2. Resonant structures of a pyrylium cation.

There are many reported synthesis methods for pyrylium salts in the literature. The most common method is the cyclodehydration of 1,5-dicarbonyl compounds, which involves an intramolecular condensation. In this method acetic anhydride is often used, which acts as both a reagent and solvent. Triphenylmethylhexachloroantimonate can also be used as an oxidizing agent. ${ }^{14}$ Another synthesis method involves isobutene diacetylation (in its gaseous form or as tert-butanol) using Bronsted acids as perchloric, tetrafluoroboric, trifluoromethanesulfonic or sulfoacetic acids or monoacetylation with tert-butylchloride, using Lewis acids $\left(\mathrm{AlCl}_{3}\right.$ or $\left.\mathrm{FeCl}_{3}\right)$ which leads to the corresponding 2,4,6-triphenylpyrylium salts. ${ }^{15}$

Alternatively, these salts can be obtained through the reaction of chalcones and acetophenones or benzaldehydes, and acetophenones using the Lewis acid boron trifluoride as the catalyst. ${ }^{16}$

García et al. (2005), ${ }^{17}$ synthesized 2,6-diphenyl-4-(p-methacryloyloxy) phenyl pyrylium tetrafluoroborate, (I) (see Scheme 1), which was used in the colorimetric detection of cyanide in water. This monomer was prepared from one equivalent of the intermediate compound 4-formylphenyl methacrylate (M-4FF), two equivalents of acetophenone and two equivalents of boron trifluoride diethyl etherate, which acts as a Lewis acid catalyst. From this monomer, a series of polymeric films, which have a maximum absorption band in the visible region at $425 \mathrm{~nm}$ and an emission band at $474 \mathrm{~nm}$, after excitation at $394 \mathrm{~nm}$ were prepared with better yield than that reported

The synthesis method in the present study involved the preparation of the methacrylic monomer, 2,6-diphenyl-4-(p-methacryloyloxy)phenyl pyrylium tetrafluoroborate $\left(\mathbf{M}_{1}\right)$ which contains a derivative from a pyrylium cation in its structure, from the intermediate compound 4-formylphenyl methacrylate (CI1) with methacrylic anhydride as the starting reagent.

\section{EXPERIMENTAL}

\subsection{Solvents and reagents.}

All solvents and reagents were of analytical or spectroscopic grade. Acetonitrile (ACN), dichloromethane, 4-(dimethylamino)-pyridine (DMAP) and boron trifluoride diethyl etherate $\left(\mathrm{BF}_{3} . \mathrm{Et}_{2} \mathrm{O}\right)$ were purchased from Merck. Methacrylic anhydride, 4-hydroxybenzaldehyde (4-HBZ) and acetophenone were acquired from Sigma-Aldrich.

\subsection{Instrumentation.}

2.2.1 ${ }^{1} \mathrm{H} \mathrm{NMR}$ and ${ }^{13} \mathrm{C}$ spectroscopy.

For different spectra, a Bruker equipment model TM ASCEND $400 \mathrm{MHz}$ resonance frequencies of $400 \mathrm{MHz}$ for ${ }^{1} \mathrm{H}$ and $100 \mathrm{MHz}$ for ${ }^{13} \mathrm{C}$ was used. The solvents were: deuterated chloroform $\left(\mathrm{CDCl}_{3}-\mathrm{d}_{1}, \mathrm{RMN}{ }^{1} \mathrm{H}\right)$ and deuterated acetonitrile $\left(\mathrm{CD}_{3} \mathrm{CN}-\mathrm{d}_{3}, \mathrm{RMN}{ }^{13} \mathrm{C}\right)$ for $\mathrm{CI}-1$; deuterated acetonitrile $\left(\mathrm{CD}_{3} \mathrm{CN}-\mathrm{d}_{3}\right.$, $\mathrm{RMN}{ }^{1} \mathrm{H}$ and $\left.{ }^{13} \mathrm{C}\right)$ for $\mathrm{M}_{1}$. The chemical shifts ( $\delta$ values) are reported in ppm. 


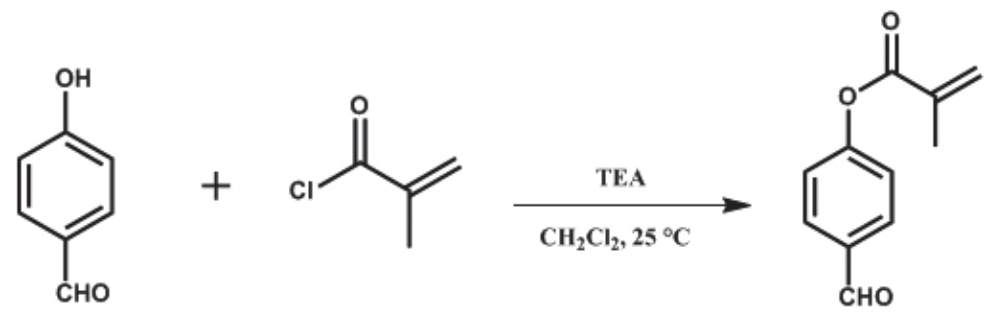

4-hydroxybenzaldehyde Methacryloyl chloride

4-formylphenyl methacrylate (M-4FF)<smiles>C=C(C)C(=O)Oc1ccc(C=O)cc1</smiles>

(M-4FF)<smiles>CC(=O)c1ccccc1</smiles>

Acetophenone<smiles>C=C(C)C(=O)Oc1ccc(-c2cc(-c3ccccc3)[o+]c(-c3ccccc3)c2)cc1</smiles>

(I)

Scheme 1. Synthetic routes for I using methacryloyl chloride as the starting reagent (García, 2005 ${ }^{1 / 7}$ ).

\subsubsection{IR spectroscopy.}

The spectra were recorded on a Nicolet FT-IR spectrophotometer (Magna 550 ) in the spectral range of 4000 to $400 \mathrm{~cm}^{-1}$ from $\mathrm{M}_{1}$ (solid) dispersed in $\mathrm{KBr}$ pills, and a drop of CI-1 (liquid) was pressed between two $\mathrm{NaCl}$ windows to obtain a plate with a thickness of $0.01 \mathrm{~mm}$ or less.

2.2.3 UV-Vis absorption spectroscopy.

The spectra were recorded using an Agilent 8453 spectrophotometer, which was controlled by Agilent Chem Station software.

2.2.4 Thin-layer chromatography (TLC).

The progress of the reactions was monitored using thin-layer chromatography (TLC) with 60F 254 silica gel plates that were $0.2 \mathrm{~mm}$ thick (Merck). A UVGL-58 Entela manual lamp with two wavelengths (254 and 365 $\mathrm{nm})$ was used as the developer.

2.3 CI-1 and $M_{1}$ synthetic processes.

$M_{1}$ was prepared according to the method of García et al (2007). ${ }^{18}$ The reaction conditions are compared in Table 1 . The synthetic routes are illustrated in Scheme 2.

Table 1. Reaction conditions to synthesize CI-1 and M, (A) Method that García (2007) used. (B) New synthesis method.

\begin{tabular}{|c|c|c|c|c|}
\hline Compound & $\begin{array}{c}\text { Starting } \\
\text { reactant }\end{array}$ & $\begin{array}{c}\mathbf{T} \\
\left({ }^{\circ} \mathrm{C}\right)\end{array}$ & $\begin{array}{c}\mathbf{t} \\
(\mathbf{h})\end{array}$ & $\begin{array}{c}\text { Yield } \\
(\%)\end{array}$ \\
\hline $\begin{array}{c}\text { M-HFF } \\
\text { (A) }\end{array}$ & $\begin{array}{c}\text { Methacryloyl } \\
\text { Cloride }\end{array}$ & 25 & 24 & 87.4 \\
\hline $\begin{array}{c}\text { I } \\
\text { (A) }\end{array}$ & $\begin{array}{c}\text { M-4FF/ } \\
\text { Acetophenone }\end{array}$ & 65 & 6 & 24 \\
$\begin{array}{c}\text { CI-1 } \\
\text { (B) }\end{array}$ & $\begin{array}{c}\text { Anhydryde } \\
\text { Methacrilic }\end{array}$ & 40 & 14 & 89.2 \\
$\begin{array}{c}\text { M1 } \\
\text { (B) }\end{array}$ & $\begin{array}{c}\text { Actophenone } \\
\text { CI/ }\end{array}$ & 68 & 12 & 32 \\
\hline
\end{tabular}

\subsubsection{Synthesis of 4-formylphenyl methacrylate (CI-1).}

In a three-necked flask (capacity $500 \mathrm{~mL}$ ) under nitrogen atmosphere, an amount of $16.73 \mathrm{~g}(137 \mathrm{mmol})$ of 4-hydroxybenzaldehyde was dissolved in $200 \mathrm{~mL}$ of dichloromethane. Then, $30.6 \mathrm{~mL}(31.68 \mathrm{~g}, 205.5 \mathrm{mmol})$ of methacrylic anhydride were added drop by drop, followed by a small amount of 4-dimethylaminopyridine (DMAP) $(0.5 \mathrm{~g})$. The reaction mixture was magnetically stirred and refluxed in a glycerine bath at $40{ }^{\circ} \mathrm{C}$ for 14 hours. Then, the flask was removed from the bath, and the product mix (4-formylphenyl methacrylate plus methacrylic acid) with $8 \% \mathrm{~m} / \mathrm{m}$ sodium bicarbonate $(3 \times 60$ $\mathrm{mL}$ ) was extracted. The organic phase was separated and dried using anhydrous sodium sulfate for $12 \mathrm{~h}$. Then, the solvent was removed by rota-evaporation to obtain a pale yellow viscous liquid. Later, a small amount of the obtained product was applied on a chromatography plate (TLC), using hexane:ethyl acetate at a proportion of $1: 1$ as the elution system. The plate was revealed with a UV-Vis lamp at a wavelength of $254 \mathrm{~nm}$, which registered only one stain. Yield: $23.22 \mathrm{~g}(89.2 \%) .{ }^{1} \mathrm{H}-\mathrm{RMN}\left(400 \mathrm{MHz} ; \mathrm{CDCl}_{3}-\mathrm{d}_{1}\right)$ : $\boldsymbol{\delta}(\mathrm{ppm}), 9.93$ $(\mathrm{s}, 1 \mathrm{H}) ; 7.85(\mathrm{~d}, 2 \mathrm{H}) ; 7.27(\mathrm{~d}, 2 \mathrm{H}) ; 6.33(\mathrm{~s}, 1 \mathrm{H}) ; 5.76(\mathrm{~s}, 1 \mathrm{H}) ; 2.01(\mathrm{~s}, 3 \mathrm{H}) .{ }^{13} \mathrm{C}-$ NMR (100 MHz; CD $\mathrm{CN}_{3}$ ) $\boldsymbol{\delta}(\mathrm{dppm}), 191.44 ; 165.21 ; 155.71 ; 135.68 ; 134.22$; $131.03 ; 122.72 ; 121.73 ; 17.60 . \mathrm{FT}-\mathrm{IR}$ (wavenumbers, $\left.\mathrm{cm}^{-1}\right): 1739.05(\mathrm{C}=\mathrm{O}$, phenolic ester); $1699.79(\mathrm{C}=\mathrm{O}$, aldehyde group); $1637.42(\mathrm{C}=\mathrm{C}$, vinyl group); $1596.13(\mathrm{C}=\mathrm{C}$, aromatic ring); 1307.52 (C-CO-O stretching); 1122.03 (O-C-C stretching); 2972.91 and 2928.81 ( $\mathrm{CH}$, methyl group); 2833.10 and 2737.21 (CH, Fermi resonance of the aldehyde group).

\subsubsection{Synthesis of 2,6-diphenyl-4-(p-methacryloyloxy) phenyl} pyryliumtetrafluoroborate $\left(M_{P}\right)$.

In a three-necked flask (capacity $250 \mathrm{~mL}$ ), under nitrogen atmosphere, 3.0 $\mathrm{g}$ (16 mmol) of CI-1 and $4.7 \mathrm{~mL}$ of acetophenone $(4.81 \mathrm{~g}, 40 \mathrm{mmol})$ were dissolved with magnetic stirring in $50 \mathrm{~mL}$ of dichloromethane. Then, $9.4 \mathrm{~mL}$ $(5.68 \mathrm{~g}, 40 \mathrm{mmol})$ of boron trifluoride diethyl etherate $\left(\mathrm{BF}_{2}\right.$.Et $\left.\mathrm{O}_{2} \mathrm{O}\right)$ was added drop by drop. The stirring continued under reflux at $68{ }^{\circ} \mathrm{C}$ for $12 \mathrm{~h}$. Then, the dark solution was precipitated with $200 \mathrm{~mL}$ of diethyl ether. The precipitate was filtered to obtain a yellow solid, which was purified by recrystallization in glacial acetic acid and resulted in yellow crystal-shaped needles ( $\mathrm{Mp}=215$ $217^{\circ} \mathrm{C}$ ). A small amount of the obtained solid in acetonitrile was dissolved and applied to a chromatographic plate (TLC) using hexane:ethyl acetate as the elution system at a proportion of 2:3. The plate was revealed with a UV-Vis lamp at a wavelength of $365 \mathrm{~nm}$, which only registered a stain. Yield: $2.46 \mathrm{~g}$ 
(32\%). ${ }^{1} \mathrm{H}-\mathrm{RMN}\left(400 \mathrm{MHz} ; \mathrm{CD}_{3} \mathrm{CN}-\mathrm{d}_{3}\right): \boldsymbol{\delta}(\mathrm{ppm}), 9.17(\mathrm{~s}, 2 \mathrm{H}) ; 8.70(\mathrm{~d}, 2 \mathrm{H})$ $8.58(\mathrm{~d}, 4 \mathrm{H}) ; 7.84(\mathrm{t}, 2 \mathrm{H}) ; 7.78(\mathrm{t}, 4 \mathrm{H}) ; 7.63(\mathrm{~d}, 2 \mathrm{H}) ; 6.37(\mathrm{~s}, 1 \mathrm{H}) ; 6.00(\mathrm{~s}, 1 \mathrm{H})$ $2.04(\mathrm{~s}, 3 \mathrm{H}) .{ }^{13} \mathrm{C}-\mathrm{NMR}\left(100 \mathrm{MHz} ; \mathrm{CD}_{3} \mathrm{CN}-\mathrm{d}_{3}\right): \delta(\mathrm{ppm}), 171.87 ; 168.13 ; 164.34$ $157.67 ; 136.46 ; 134.23 ; 132.48 ; 131.11 ; 130.05 ; 129.76 ; 129.02 ; 126.09$
124.61; 116.67, 18.97.FT-IR (wavenumbers, $\left.\mathrm{cm}^{-1}\right)$ : $1737.22(\mathrm{C}=\mathrm{O}$, phenolic ester $) ; 1627.55(\mathrm{C}=\mathrm{C}$, vinyl group $) ; 1590.02,(\mathrm{C}=\mathrm{C}$, aromatic ring $) ; 1224.84$ (C-CO-O stretching); 1114.30 (O-C-C stretching).

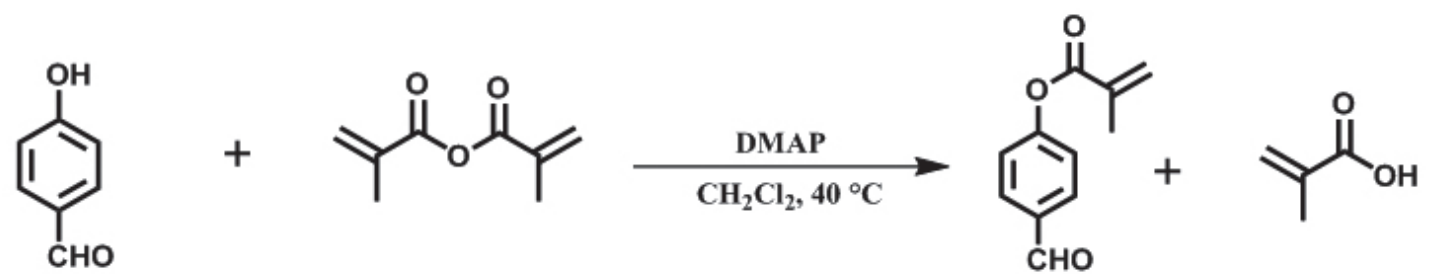

4-hydroxybenzaldehyde Methacrylic anhydride

(CI-1)

Methacrylic acid

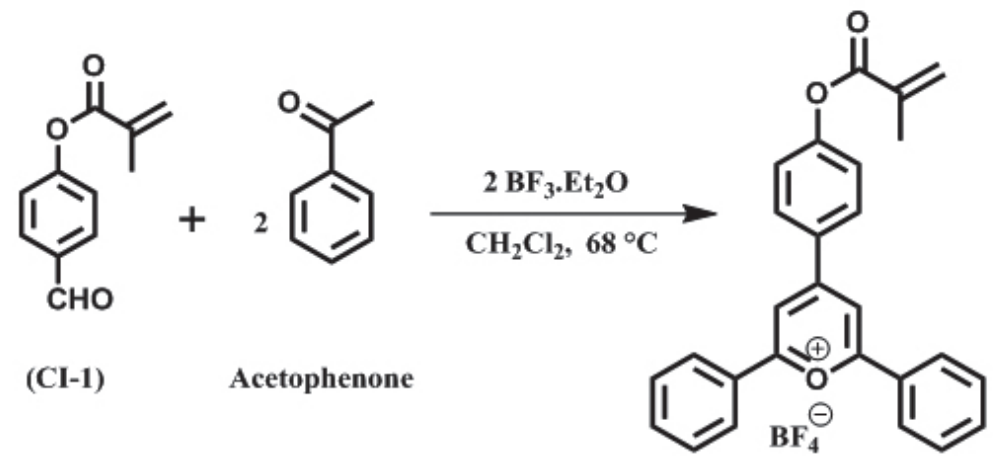

$\left(\mathrm{M}_{1}\right)$

Scheme 2. Synthetic routes for CI-1 and $\mathrm{M}_{1}$ using methacrylic anhydride as the starting reagent.

\section{RESULTS AND DISCUSSION}

CI-1 synthesis is a typical esterification reaction that involves a hydroxyl group (4-hydroxybenzaldehyde) and an anhydride (methacrylic anhydride) to form the ester (methacrylate 4-formylphenyl, CI-1) and the corresponding carboxylic acid (methacrylic acid). Methacrylic acid was removed from the reaction products (in its sodium salt form) by extraction using an aqueous solution of $8 \% \mathrm{~m} / \mathrm{m}$ sodium bicarbonate.
Meanwhile, $\mathrm{M}_{1}$ synthesis corresponds to a Claisen-Schmidt crossed aldol condensation, in which a cyclodehydration occurs and is catalyzed by the Lewis acid $\mathrm{BF}_{3}$. Initially, one equivalent of acetophenone and one equivalent of aldehyde react to form a carbonyl $\boldsymbol{\alpha}, \boldsymbol{\beta}$ unsaturated intermediate, which is subsequently condensed with a second equivalent of acetophenone to form $\mathrm{M}$ (see Scheme 3).

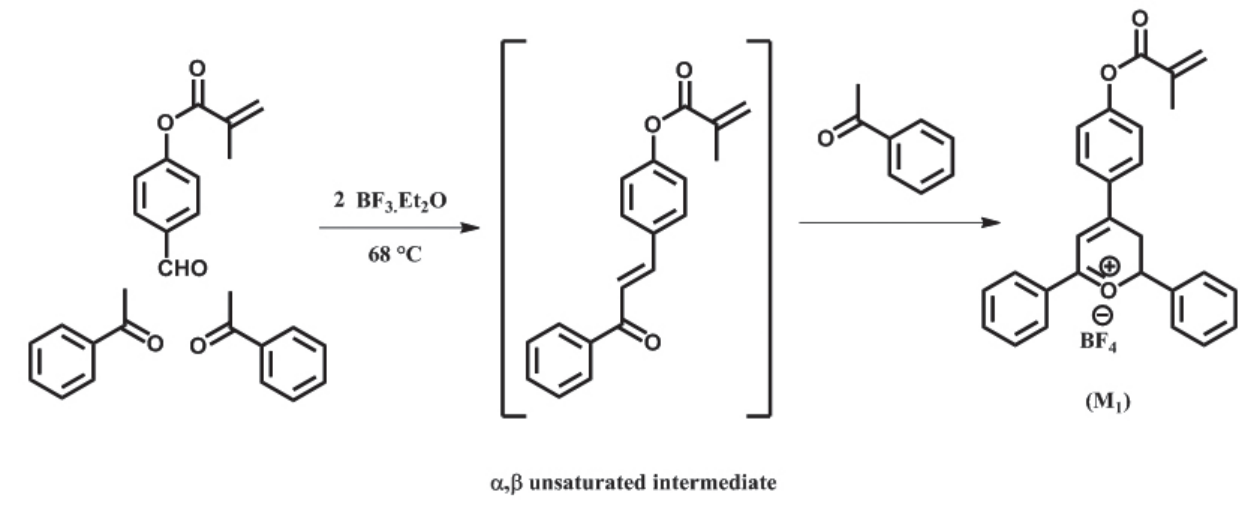

Scheme 3. Formation of $M_{1}$ from a carbonyl $\boldsymbol{\alpha}, \boldsymbol{\beta}$ unsaturated intermediate.

This new method developed is notably better (see Table 1) that those previously mentioned in the literature for CI- $1^{19,20}$ and $M_{1}$. Significantly, for the first time CI-1 was synthesized with methacrylic anhydride as the starting reagent. The highest reaction yield in this synthesis could be associated with the excellent catalytic properties of DMAP used. Although the synthesis of M from CI-1 has been reported, a better yield that the reported by García (2007) ${ }^{1}$ was obtained, which could be explained as follows: with raising of temperature in $3{ }^{\circ} \mathrm{C}$, increases the number of molecules that reach the activation energy, which favors the formation of product. In this synthesis, the activation energy is achieved more efficiently in relatively long times, since by doubling the reaction time a higher yield (percentage) is obtained.

On the other hand, the UV-Vis absorption spectrum of $M_{1}$ (see Fig. 3) shows two wavelengths of maximum absorption at 305 and $416 \mathrm{~nm}$ because of the charge transfer bands, ${ }^{21}$ which are induced by the $2,4,6$ trisubstituted pyrylium cation. 


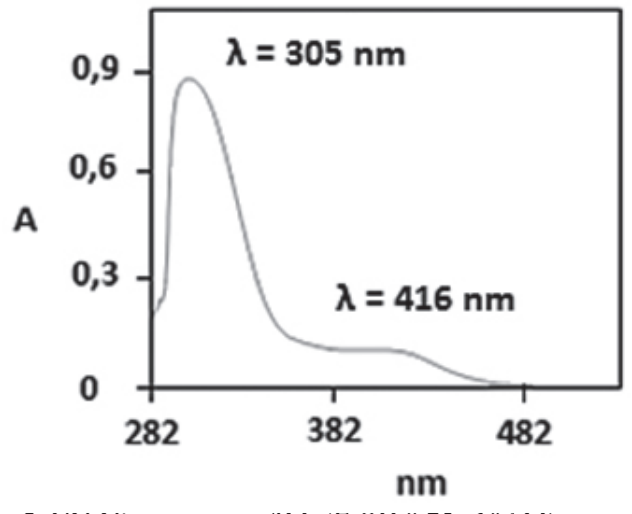

Figure 3. UV-Vis spectrum of $\mathrm{M}_{1}\left(\mathrm{EtOH} 8.75 \times 10^{-4} \mathrm{M}\right)$.

\section{CONCLUSIONS}

Higher reaction performances were obtained in the synthesis of CI-1 using methacrylic anhydride as the starting reagent instead of methacryloyl chloride. Although $\mathrm{M}_{1}$ was synthesized from CI-1, the variation of certain conditions such as the temperature and reaction time leads to higher yields.

\section{ACKNOWLEDGMENTS}

Saul Bustamante thanks the CONICYT Scholarship for the PhD program in Chile for foreigners, 2014 No. 63140086 and at the Polymer Laboratory at the University of Concepcion, Chile.

\section{REFERENCES AND NOTES}

1. Balaban, A. T. Aromaticity of six-membered rings with one heteroatom. Top. Heterocycl. Chem. 2, 1-44 (2008).

2. Balaban, A. T. et al. Pyrylium Salts: Syntheses, Reactions, and Physical Properties (1204 Literaturzitate). Adv. Heterocycl. Chem. Suppl. 2, (1982).

3. Sawada, G. A. et al. Chalcogenopyrylium dyes as inhibitors/modulators of P-glycoprotein in multidrug-resistant cells. Bioorg. Med. Chem.16, 9745-9756 (2008)

4. Okamoto, T. \& Yamamoto, Nobuko Kawaguchi, M. Pharmaceutical compositions containing pyrylium compounds, pyrylium salts and process for manufacturing a medicament containing the aforesaid compounds. $1-30$ (2000).

5. Rao, B. A., Lee, J.-Y. \& Son, Y.-A. Synthesis of a novel pyrylium salt with chemoselectivity to a cyanide anion. Supremol. Chem.27, 191-200 (2015).
6. Santamaria, J. \& Valdes, C. Six-Membered Rings with One Oxygen: Pyrylium Ion, Related Systems and Benzo-Derivatives. Mod. Heterocycl. Chem. 1631-1682 (2011).

7. Heidarizadeh, F. \& Abadast, F. Reactions of some nucleophiles with pyrylium salts. Orient. J. Chem. 27, 1421 (2011).

8. Ampliación de Química Orgánica Avanzada. Capítulo 7. Heterociclos Aromáticos de seis Miembros con Oxígeno 1-8 Available at: https:// riuma.uma.es/xmlui/bitstream/handle/10630/7518/Tema_7.Heterociclos aromaticos_con_oxigeno.pdf?sequence=1. (Accessed: 27 th April 2017)

9. Milov, A. A., Starikov, A. G., Gridin, M. K. \& Minyaev, R. M. Effect of the counterion on the steric and electronic structure of pyrylium cation. Russ. J. Gen. Chem. 77, 1373-1385 (2007).

10. Bhowmik, P. K., Burchett, R. A., Han, H. \& Cebe, J. J. Synthesis and characterization of poly (pyridinium salt) $\mathrm{s}$ with organic counterion exhibiting both lyotropic liquid-crystalline and light-emitting properties. J. Polym. Sci. Part A Polym. Chem.39, 2710-2715 (2001).

11. Ruiz Guerrero, R. et al. Catalytic synthesis of $1,3,5$-triphenylbenzenes, $\beta$ -methylchalcones and 2, 4, 6-triphenyl pyrylium salts, promoted by a super acid triflouromethane sulfonic clay from acetophenones. J. Mex. Chem. Soc. 50, 114-118 (2006).

12. Harmsen, S. et al. Rational design of a chalcogenopyrylium-based surface-enhanced resonance Raman scattering nanoprobe with attomolar sensitivity. Nat. Commun.6, (2015).

13. Wang, L. et al. Conjugated poly (pyridinium salt) s as fluorescence lightup probes for heparin sensing. J. Appl. Polym. Sci.131, (2014).

14. Joule, J. A. \& Mills, K. Heterocyclic chemistry. (John Wiley \& Sons, 2008).

15. Balaban, A. T. 8.1 Balaban--Nenitzescu--Praill Reaction. Six-Membered Heterocycles 402 (2011).

16. Franconetti, A., Contreras-Bernal, L. \& Cabrera-Escribano, F. From Pyrylium to Pyridinium Salts: Understanding Physicochemical Features. in Proceedings of The 17th International Electronic Conference on Synthetic Organic Chemistry (2013).

17. García, F. et al. Pyrylium-containing polymers as sensory materials for the colorimetric sensing of cyanide in water. Chem. Commun. 2790-2792 (2005).

18. Acosta, B. G. Sensores químicos cromogénicos y fluorogénicos para la detección de iones y moléculas neutras. (Universidad Politécnica de Valencia, 2007).

19. San José Pascual, N. Síntesis de polímeros que incorporan sistemas receptores de aniones: estudio de sus aplicaciones como dosímetros y sensores. (Universidad de Burgos, 2007).

20. Naveau, H. P. Infrared, NMR and mass spectra of the methacrylates or methacrylate-anhydride of five phenolic compounds. Spectrochim. Acta Part A Mol. Spectrosc. 28, 651-658 (1972).

21. Grabowski, Z. R., Rotkiewicz, K. \& Rettig, W. Structural changes accompanying intramolecular electron transfer: focus on twisted intramolecular charge-transfer states and structures. Chem. Rev.103, 3899-4032 (2003). 